\section{Hypotension associated with advanced Hodgkin lymphoma}

\author{
Ankit Mangla, ${ }^{1}$ Geetanjali Dang,' \\ Hussein Hamad, ${ }^{1}$ Roozbeh Mohajer, ${ }^{2}$ \\ Rosalind Catchatourian, ${ }^{2}$ Paula Kovarik ${ }^{3}$ \\ ${ }^{1}$ Department of Internal Medicine, \\ 2Division of Hematology and Oncology, \\ ${ }^{3}$ Department of Pathology, John H. \\ Stroger Jr. Hospital of Cook County, \\ Chicago, IL, USA
}

\section{Abstract}

Hypotension is an extremely rare manifestation of Hodgkin lymphoma. We report the case of a patient who presented with new onset hypotension and was diagnosed with urosepsis and septic shock requiring pressor support for maintaining his blood pressure. computed tomography (CT) scan of abdomen showed liver lesions, which were new on comparison with a CT abdomen done 3 weeks back. Biopsy of the liver lesions and subsequently a bone marrow biopsy showed large atypical Reed-Sternberg cells, positive for CD15 and CD 30 and negative for CD45, CD3 and CD20 on immuno-histochemical staining, hence establishing the diagnosis of Hodgkin lymphoma. The mechanism involved in Hodgkin lymphoma causing hypotension remains anecdot$\mathrm{al}$, but since it is mostly seen in patients with advanced Hodgkin lymphoma, it is hypothetically related to a complex interaction between cytokines and mediators of vasodilatation. Here we review relevant literature pertaining to presentation and pathogenesis of this elusive and rare association.

\section{Introduction}

Koreich in 1981 first reported the case of a 22 year old man diagnosed as Hodgkin lymphoma (HL) who developed hypothermia and hypotension during the course of his admission, which resolved only after initiation of chemotherapy. ${ }^{1}$ Systemic symptoms are present in a third of patients at presentation and among them fever is the most common followed by night sweats and weight loss. ${ }^{2}$ On review of literature, we found 18 case reports with similar finding of hypotension and hypothermia associated with HL. Most of the patients in these case reports developed hypotension and hypothermia after initiation of chemotherapy. Only 3 out of these 18 patients were found to have hypotension at the time of presentation prior to diagnosis. We report the case of a patient who presented with hypotension and hypothermia and was diagnosed initially with septic shock. He was found to have ill-defined liver lesions on the computed tomography (CT) scan which were new on comparison with a recent $\mathrm{CT}$ abdomen done for evaluation of nephrolithiasis. Biopsy of the liver lesions and bone marrow biopsy showed a diagnosis of HL. The pathophysiology of development of hypotension and hypothermia in patients during chemotherapy or prior to diagnosis remains unexplained. A complex interaction between cytokines, tumor and blood vessels has been proposed as the genesis of such a presentation. The pathogenesis of such an association however remains anecdotal and warrants further consideration.

\section{Case Report}

A 61 year old man presented to emergency room with history of flank pain on right side, dysuria, urgency and frequency with occasional hematuria for 3 days associated with fever, chills and rigors. 3 weeks before this presentation he was admitted for renal colic and was found to have a new staghorn calculus in the kidney which was managed conservatively with 7 days of oral antibiotics. Review of systems noted a history of 40 pounds weight loss over 3 months, drenching night sweats and occasional low grade fevers for last 3 months. Past medical history was significant for multiple episodes of renal colic secondary to nephrolithiasis treated with lithotripsy several years ago. Social history was significant for 30 pack year history of smoking, occasional alcohol consumption and no substance abuse or high risk behavior. Family history and medication history were not contributory. At the time of presentation patient was noted to be hypotensive with a blood pressure (BP) of $78 / 49 \mathrm{mmHg}$ and mean arterial pressure (MAP) of $59 \mathrm{mmHg}$. The hypotension was new compared with recent admission 3 weeks prior, where the BP readings were consistently above a MAP of 80 . The hypotension did not correct with bolus of 3 liters of $0.9 \%$ normal Saline (NS) and in view of his history of dysuria and intermittent hematuria and recent diagnosis of staghorn calculus he was diagnosed with urinary tract infection (UTI) leading to urosepsis and septic shock. He was admitted to medical intensive care unit (MICU) where he was started on pressor support with norepinephrine and broad spectrum antibiotic coverage with vancomycin and piperacillin-tazobactam. Vitals recorded at presentation were temperature of $97.3^{\circ} \mathrm{F}$, BP of $78 / 49 \mathrm{mmHg}$, MAP of $59 \mathrm{mmHg}$, heart rate $80 / \mathrm{min}$, respiratory rate $18 / \mathrm{min}$, $\mathrm{Sp02}$ of $98-99 \%$ on room air. General exam was significant for an averaged sized man in mild
Correspondence: Ankit Mangla, Department of Internal Medicine, John H. Stroger Jr. Hospital of Cook County, 1901 West Harrison Street, Chicago, IL 60612, USA.

Tel.: + 1.312.513.7437.

E-mail: ankit.mangla.md@gmail.com

Key words: Hodgkin lymphoma, hypotension, liver metastasis.

Contributions: AM wrote and rewrote the manuscript as per the critique provided by co-authors and reviewers; GD searched the references and provided critique to the manuscript; $\mathrm{HH}$ wrote the abstract and searched the references; RM searched the references and provided critique to the manuscript; $\mathrm{RC}$ provided the expert opinion and critique to the manuscript; PK provided the expert opinion on the histopathology and gave critique to the manuscript.

Conflict of interests: the authors declare no potential conflict of interests

Received for publication: 26 July 2014

Revision received: 27 August 2014.

Accepted for publication: 29 August 2014.

This work is licensed under a Creative Commons Attribution NonCommercial 3.0 License (CC BYNC 3.0).

(C) Copyright A. Mangla et al., 2014

Licensee PAGEPress, Italy

Hematology Reports 2014; 6:5572

doi:10.4081/hr.2014.5572

distress with mild pallor, no icterus, cyanosis or edema. Systemic exam was significant for mild right costovertebral angle tenderness. Labs were significant for hemoglobin $(\mathrm{Hb})$ of 9.2 $\mathrm{g} / \mathrm{dL}$, mean corpuscular volume (MCV) of 77.6 fL and leukocyte count (WBC) of $5.1 \mathrm{k} / \mu \mathrm{L}$ with differential of $77 \%$ neutrophils. Liver enzymes showed alkaline phosphatase of $212 \mathrm{U} / \mathrm{L}$, Alanine transaminase (ALT) $80 \mathrm{U} / \mathrm{L}$, Aspartate tranaminase (AST) $96 \mathrm{U} / \mathrm{L}$, Total protein 3.6 $\mathrm{g} / \mathrm{dL}$ and albumin $1.5 \mathrm{~g} / \mathrm{dL}$. Urine dipstick was positive for blood (1+), proteins (30) and glucose (50) and urine microscopy showed 109 $\mathrm{RBC}$ and $12 \mathrm{WBC}$. Rest of the lab results are shown in Table 1. Cortisol level at admission was $182.6 \mathrm{mg} / \mathrm{dL}$ which ruled out adrenal insufficiency. Two sets of blood culture and urine culture were done prior to starting antibiotics which showed no growth after 5 days of incubation. CT scan abdomen done at presentation showed numerous ill defined lesions in the liver which were new from the CT scan done 3 weeks before for evaluation of renal colic (Figure 1). The study redemonstrated the staghorn calculus with no evidence of obstruction, no radiographic evidence of pyelonephritis or renal abscess. Patient received 2 days of pressor support with Norepinephrine drip, fol- 
lowing which his blood pressure improved to a MAP over $70 \mathrm{mmHg}$, however he continued to have intermittent episodes of hypotension which were managed with frequent boluses of 1000 to $500 \mathrm{~mL}$ of $0.9 \% \mathrm{NS}$. Interestingly, on Day 5 of admission, patient developed increased shortness of breath and became hypoxic. Trans-thoracic echocardiogram done at bedside showed normal ejection fraction and normal inferior vena cava. Patient was diagnosed with fluid overload secondary to frequent fluid boluses and was given one dose of $20 \mathrm{mg}$ i.v. lasix which led to resolution of shortness of breath. During this entire stay, he continued to have intermittent episodes of hypotension with mean arterial pressure dropping to low 60's. Colonoscopy and esophago-gastro-duodenoscopy (EGD) done as part of malignancy workup, showed 2 polyps which were diagnosed as tubular adenoma and thick gastric folds with chronic gastritis on histopathology respectively. A liver biopsy was planned after improvement in his overall condition however on day 9 of the hospitalization patient declined the procedure and requested a break from the hospital. Liver biopsy was deferred for a later date and patient was discharged in a stable condition. During this admission 4 blood cultures and 3 urine cultures did not show any growth after 5 days of incubation. He was discharged with oral levofloxacin to complete a course of 14 days of antibiotics for complicated UTI. Three days after being discharged from hospital, patient returned to emergency room with similar complaints of acute onset weakness and fatigue and a single episode of fever for which he received a single dose of Ibuprofen at home. Vitals at presentation showed rectal temperature of $94.1^{\circ} \mathrm{F}$, BP of $84 / 49 \mathrm{mmHg}$, mean arterial pressure of $60 \mathrm{mmHg}$, breathing at rate of $18 / \mathrm{min}$, heart rate $59 / \mathrm{min}$ and saturating $97 \%$ on room air. Examination this time was unremarkable. All labs at readmission are shown in Table 1. Patient was readmitted to MICU with a provisional diagnosis of urosepsis and was given vancomycin and piperacillin-tazobactam. Blood culture and urine culture done at this time again showed no growth which could support the diagnosis of sepsis. Biopsy of the liver lesions showed extensive lymphocytic and histiocytic infiltrates with abnormally large cells and positive stains for CD15 and CD30. Bone marrow biopsy also showed areas of residual trilineage hematopoesis with $40 \%$ cellularity alongwith several para-trabecular infiltrates composed of large atypical cells including ReedSternberg (RS) cells, in a mixed inflammatory background consisting of small lymphocytes, histiocytes, eosinophils and plasma cells (Figure 2). The immuno-histochemical stains were positive for CD15 and CD30 and negative for CD45, CD3 and CD20. Bone marrow aspirate showed trilineage hematopoesis with orderly maturation. A 100 cell count showed granulocytes (56\%), monocytes (1\%), eosinophils (6\%), erythroid precursors (34\%), lymphocytes (2\%) and plasma cells (1\%). The presence of the characteristic RS cell in a mixed inflammatory background pointed towards a diagnosis of HL. The diagnosis was further confirmed by positive immune-histochemical (IHC) stain for CD15 and CD30 alongwith negative IHC stain for CD45, CD3 and CD20. Since no pan-T antigens were missing, the possibility of a T-cell lymphoma was very low. A CT Chest for staging did not show any hilar lymphadenopathy. Soon after the diagno-

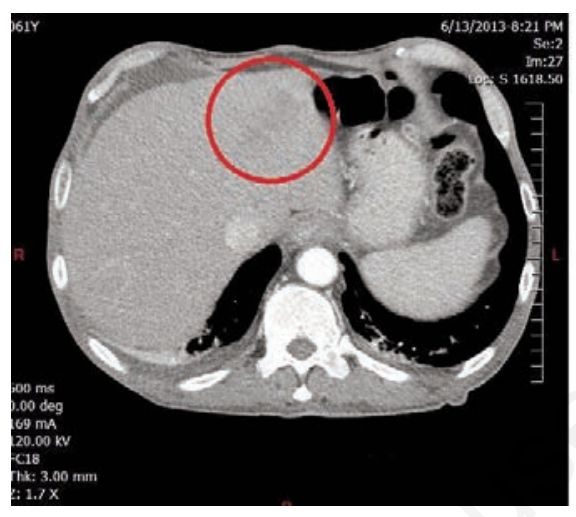

Figure 1. Ill defined lesions seen in the liver.

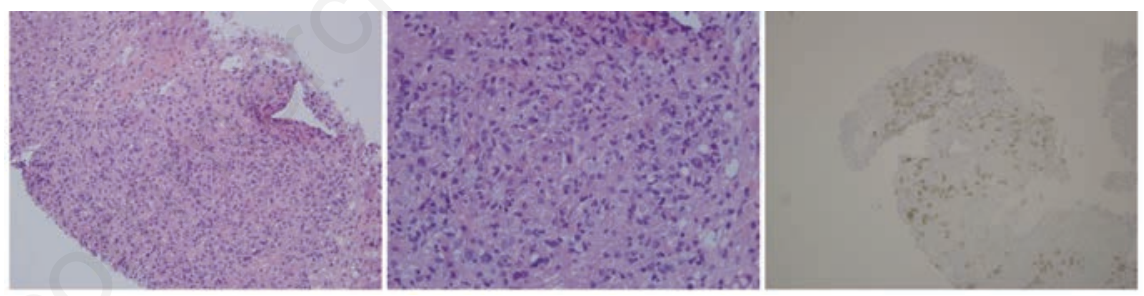

Figure 2. Extensive Lymphocytic, histiocytic infiltrates with abnormal large cells and positive staining for CD 15 and CD 30 (From left to right).

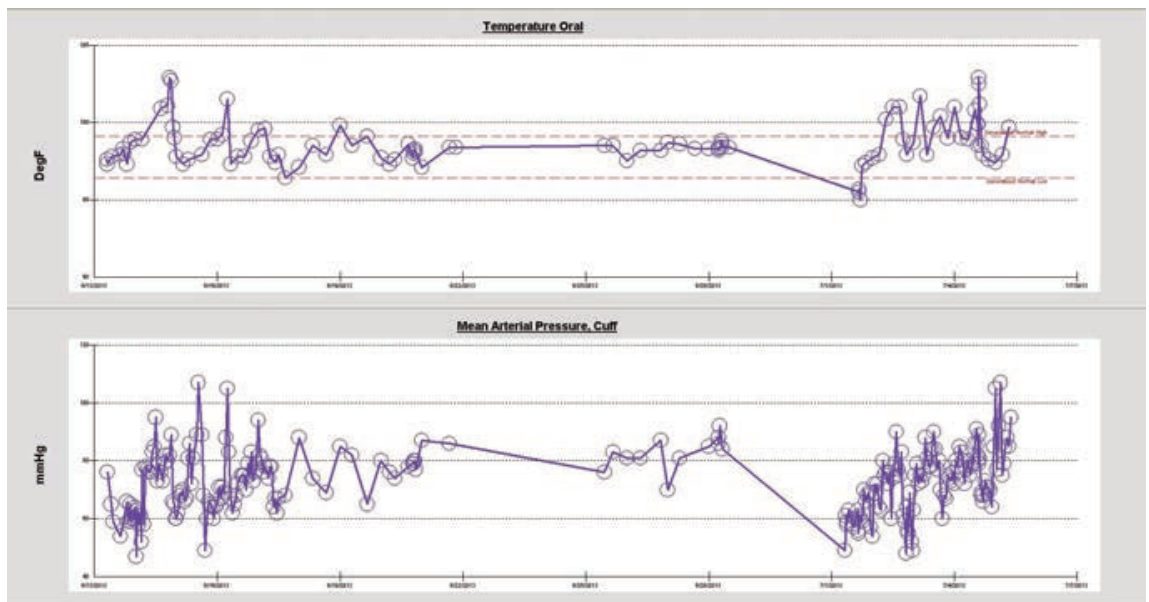

Figure 3. Graphs of the blood pressure and temperature curves of this patient during first and second admission (combined).

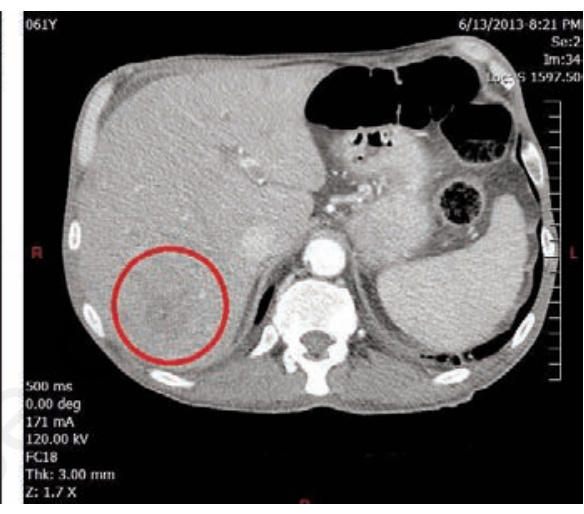

sis patient was started on chemotherapy with doxorubicin, dacarbazine, vinblastine. Bleomycin was initially withheld due to unknown pulmonary function in view of patient been active smoker and was added later after pulmonary function test turned out to be normal. After completion of the $1^{\text {st }}$ cycle of chemotherapy the blood pressure started improving to a MAP of more than $80 \mathrm{mmHg}$ continues to be free of any episode of hypotension or hypothermia. 


\section{Discussion and Conclusions}

Koreich et al. in 1981 reported the first patient with HL who developed hypothermia and hypotension during the course of admission, prior to initiation of chemotherapy. ${ }^{1}$ Since then 18 more cases have been reported with hypothermia as presenting feature and in 8 out of 18 patients, hypotension has also been recorded (Table 2). ${ }^{1,3-17}$ Fifteen out of 18 patients reported in literature had developed these symptoms after initiation of chemotherapy with only 3 patients presenting with hypotension prior to diagnosis. Interestingly, most of the patients described with hypothermia and hypotension have been reported to have liver metastases. To date, the mechanism behind hypotension and hypothermia as isolated manifestations of HL remains unexplained. In our patient we ruled out all the alternative causes of hypotension. Though the presenta- tion of the patient was highly suggestive of urosepsis, numerous blood and urine cultures did not grow any microbe which could have explained the cause of sepsis. Moreover treatment with vancomycin and piperacillintazobactam did not lead to improvement in the condition of the patient, essentially ruling out infectious cause and sepsis as the primary cause of hypotension. An increased random and morning cortisol level and TSH/Free T4 level ruled out adrenal insufficiency and thy-

Table 1. Labs at first and second admission.

\begin{tabular}{|c|c|c|}
\hline Labs & At first admission & At second admission \\
\hline $\begin{array}{l}\text { Basic metabolic profile } \\
\text { Sodium }(135-145 \mathrm{mEq} / \mathrm{L}) \\
\text { Chloride }(100-110 \mathrm{mEq} / \mathrm{L}) \\
\text { Bicarbonate }(23-31 \mathrm{mEq} / \mathrm{L}) \\
\text { Potassium }(3.0-5.0 \mathrm{mEq} / \mathrm{L}) \\
\text { BUN }(8-20 \mathrm{mg} / \mathrm{dL}) \\
\text { Creatinine }(0.6-1.4 \mathrm{mg} / \mathrm{dL}) \\
\text { S. Glucose }(65-110 \mathrm{mg} / \mathrm{dL}) \\
\text { Calcium }(8.5-10.5 \mathrm{mg} / \mathrm{dL}) \\
\text { Magnesium }(1.8-2.7 \mathrm{mg} / \mathrm{dL}) \\
\text { Phosphorus }(2.5-4.5 \mathrm{mg} / \mathrm{dL})\end{array}$ & $\begin{array}{l}133 \\
104 \\
21 \\
4.0 \\
11 \\
0.4 \\
93 \\
7.3 \\
1.4 \\
4.1\end{array}$ & $\begin{array}{l}137 \\
107 \\
21 \\
3.7 \\
10 \\
0.4 \\
114 \\
7.0 \\
- \\
-\end{array}$ \\
\hline $\begin{array}{l}\text { Complete blood count } \\
\text { Hemoglobin }(12.9-16.8 \mathrm{~g} / \mathrm{dL}) \\
\text { Hematocrit }(\%) \\
\text { MCV }(81.9-97.8 \mathrm{fL}) \\
\text { WBC }(4.4-10.6 \mathrm{k} / \mu \mathrm{L}) \\
\text { Differential } \\
\text { Platelet count }(161-369 \mathrm{k} / \mu \mathrm{L}) \\
\text { Ferritin }(23.9-336.0 \mathrm{ng} / \mathrm{mL}) \\
\end{array}$ & $\begin{array}{c}9.2 \\
29.1 \\
77.6 \\
5.1 \\
\text { P(54) Bands(20) L(10) M(15) } \\
354 \\
10,651\end{array}$ & $\begin{array}{c}7.9 \\
24.6 \\
76.7 \\
3.8 \\
\text { P(77) Bands (4) L(6) M(13) } \\
259 \\
>1500\end{array}$ \\
\hline $\begin{array}{l}\text { Liver enzymes } \\
\text { Total protein }(6.4-8.3 \mathrm{~g} / \mathrm{dL}) \\
\text { Albumin }(3.8-5.2 \mathrm{~g} / \mathrm{dL}) \\
\text { Total Bilirubin }(0.2-1.2 \mathrm{mg} / \mathrm{dL}) \\
\text { Direct Bilirubin }(0.0-0.2 \mathrm{mg} / \mathrm{dL}) \\
\text { Alanine transaminase }(0-40 \mathrm{U} / \mathrm{L}) \\
\text { Aspartate transaminase }(5-35 \mathrm{U} / \mathrm{L}) \\
\text { Alkaline phsophatase }(50-120 \mathrm{U} / \mathrm{L}) \\
\gamma \text {-Glutamyl transferase }(3-60 \mathrm{U} / \mathrm{L}) \\
\text { Lactate dehydrogenase }(85-210 \mathrm{U} / \mathrm{L}) \\
\text { Cholesterol }(130-240 \mathrm{mg} / \mathrm{dL})\end{array}$ & $\begin{array}{c}3.6 \\
1.5 \\
0.8 \\
0.4 \\
80 \\
91 \\
212 \\
36 \\
165 \\
100\end{array}$ & $\begin{array}{c}4.2 \\
1.9 \\
1.2 \\
0.7 \\
44 \\
85 \\
184 \\
41 \\
154 \\
103\end{array}$ \\
\hline $\begin{array}{l}\text { Urinalysis } \\
\text { Sp. Gravity } \\
\text { pH (5.0-7.0) } \\
\text { RBC (0-3/ HPF) } \\
\text { WBC (0-3/ HPF) }\end{array}$ & $\begin{array}{c}1.015 \\
6.0 \\
109 \\
12\end{array}$ & $\begin{array}{c}1.009 \\
6.0 \\
178 \\
1\end{array}$ \\
\hline $\begin{array}{l}\text { Endocrinology } \\
\text { Cortisol Random }(\mu \mathrm{g} / \mathrm{dL}) \\
\text { Cortisol AM } \\
\text { TSH }(0.34-5.60 \mu \mathrm{IU} / \mathrm{mL}) \\
\text { Free T4 }(0.58-1.64 \mathrm{ng} / \mathrm{dL})\end{array}$ & $\begin{array}{c}\text { Day } 1 \text { - } 182.6 \\
\text { Day } 6 \text { - } 20.73 \\
- \\
-\end{array}$ & $\begin{array}{c}\text { Day } 1-41.71 \\
\text { Day } 7-22.19 \\
0.380 \\
0.89\end{array}$ \\
\hline $\begin{array}{l}\text { Miscellaneous } \\
\text { HIV ELISA } \\
\text { Sedimentation Rate }(0-32 \mathrm{~mm} / \mathrm{hr}) \\
\text { C-Reactive Protein }(0.0-0.5 \mathrm{mg} / \mathrm{dL}) \\
\text { Hepatitis B } \\
\text { Hepatitis A (Antibody) } \\
\text { Hepatitis C (Antibody) } \\
\text { ANA panel } \\
\text { ANCA panel } \\
\text { Rheumatoid factor (<20 IU/mL) } \\
\text { C3 (88-201 mg/dL) } \\
\text { C4 (16-47 mg/dL) }\end{array}$ & $\begin{array}{c}\text { Negative } \\
- \\
- \\
- \\
- \\
- \\
- \\
- \\
- \\
-\end{array}$ & $\begin{array}{c}\text { Negative } \\
78 \\
21.70 \\
\text { Positive } \\
\text { Positive } \\
\text { Negative } \\
\text { Negative } \\
\text { Negative } \\
<20 \\
135 \\
27\end{array}$ \\
\hline
\end{tabular}




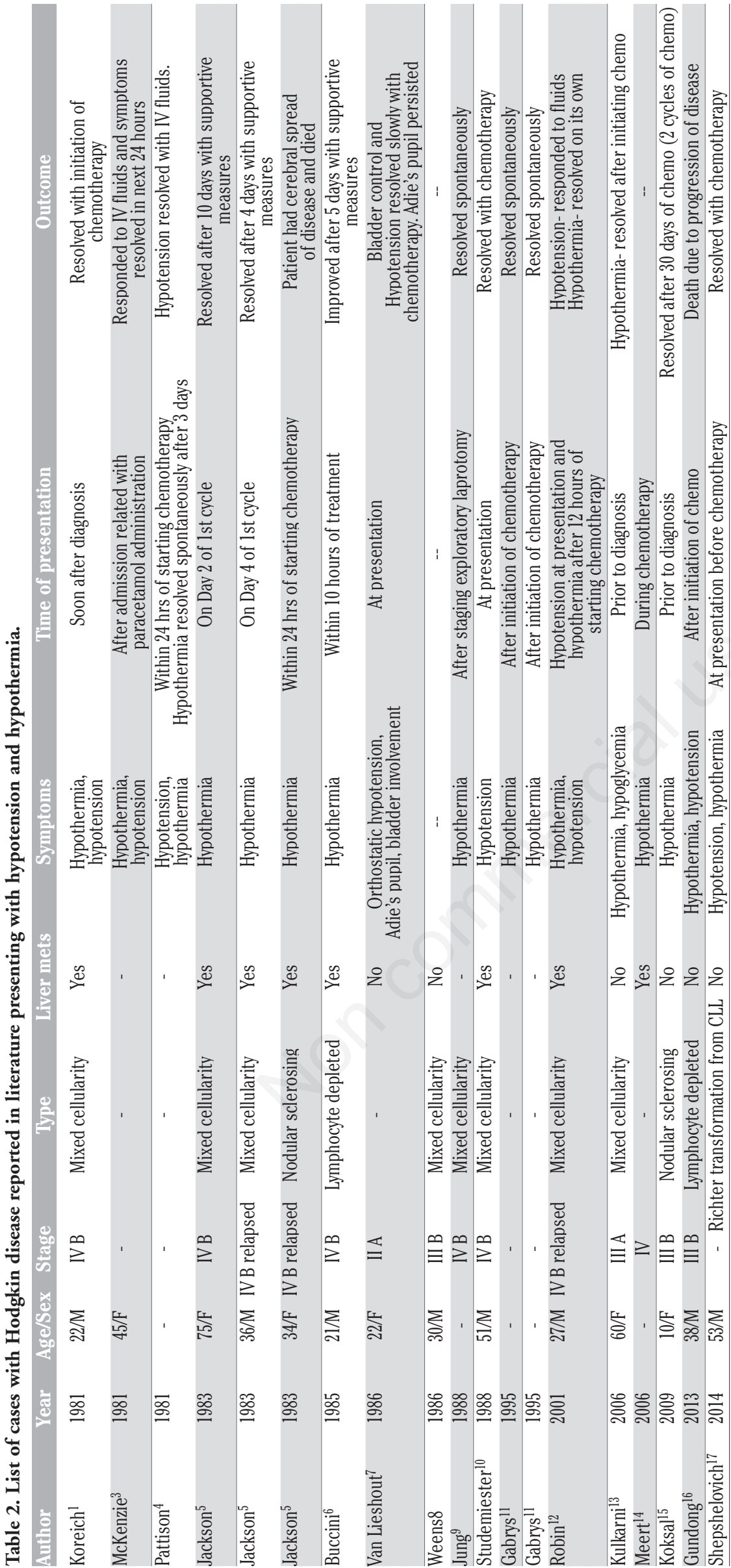

roid involvement respectively. A normal transthoracic echocardiogram demonstrated a normal cardiac anatomy and clinically there were no signs of heart failure. Though orthostatic maneuver was not done in our patient because of his general condition, the absence of correction of hypotension with volume repletion and fluid boluses makes hypovolemia less likely.

Blood pressure control is governed by a complex interaction between cardiac, renal, endocrine and nervous systems. ${ }^{18}$ Hypotension in cancer patients has long being believed to be secondary to cytokine release from increased macrophage function. ${ }^{19}$ The cytokines implicated in causing hypotension are Interleukin (IL)1 and IL-2, Tumor Necrosis Factor- $\alpha$ (TNF- $\alpha$ ) and Interferon- $\alpha$ (IF- $\alpha) .{ }^{20}$ Although the exact mechanism of TNF- $\alpha$ causing hypotension is not clear, it is well known that administration of TNF- $\alpha$ leads to production of nitric oxide (NO) which is a potent vasodilator and could lead to hypotension. ${ }^{21,22}$ In addition to this, cytokines also cause endothelial damage, a mechanism which is very well defined in patients with sepsis and septic shock. In patients with sepsis infection is the primary cause of activation of macrophage and release of cytokines..$^{20}$ Another important association implicated in this patient is the effect of psycho-neuroendocrine hormones in mediation of NO, like melatonin, which has been shown to have counter-regulatory effect on action of free radicals, especially No. ${ }^{23}$ We postulate from the above, that the probable cause of hypotension in this patient could be release of cytokines from the tumor especially from liver metastasis, which is an extremely vascular organ. Autonomic dysfunction is a know paraneoplastic syndrome associated with HL which raises the possibility of direct infiltration of hypothalamus or pineal gland by the tumor leading to alteration in neuroendocrine hormones. The loss of inhibition of counter-regulatory effects of these hormones on cytokine regulation could result in macrophage activation and NO production resulting in hypotension. ${ }^{24}$ Salicylates have also been postulated to have a role in hypothalamic hypersensitivity. ${ }^{12}$ Our patient never took any salicylates for his fever which rules this out as a possible cause. Moreover, not all patients reported were taking NSAIDS before presentation, making this explanation less likely.

In conclusion, hypotension may be associated directly with Hodgkin Lymphoma. Although, further studies are needed in support of this association, we can conclude from this case that the condition responds dramatically to aggressive chemotherapy.

\section{References}

1. Koriech OM. Hypothermia and hypoten- 
sion in Hodgkin's disease. Br Med J 1981;282:1582-3.

2. Gobbi PG, Ferreri AJM, Ponzoni M, et al. Hodgkin lymphoma. Crit Rev Oncol Hematol 2013;85:216-37.

3. MacKenzie J. Hypothermia and hypotension in Hodgkin's disease. Br Med J (Clin Res Ed) 1981;283:139-40.

4. Pattison CW. Hypothermia and hypotension in Hodgkin's disease. Br Med J (Clin Res Ed) 1981;283:438.

5. Jackson MJ, Proctor SJ, Leonard RC. Hypothermia during chemotherapy for Hodgkin's disease. Br Med J (Clin Res Ed) 1983;286:1183-4.

6. Buccini RV. Hypothermia in Hodgkin's disease. N Engl J Med 1985;312:244.

7. Van Lieshout JJ, Wieling W, Van Montfrans GA, et al. Acute dysautonomia associated with Hodgkin's disease. J Neurol Neurosurg Psychiatry 1986;49:830-2.

8. Weens JH, Hernandez B. Hypothermia following chemotherapy for Hodgkin's disease. Cancer Treat Rep 1986;70:313-4.

9. Jung M, Koppensteiner R, Graninger W, et al. Hypothermia in Hodgkin's disease after exploratory laparotomy. Klin Wochenschr 1988;66:552-5.
10. Studemeister A, Ptacin M, Cunningham C, et al. Unexplained hypotension in Hodgkin's disease. Cardiology 1988;75: 154-6.

11. Gabry K, Mazur G. Hypothermia during chemotherapy for lymphomas. Pol Arch Med Wewn 1995;93:130-4.

12. Robin V, Lebacq J, Michaux L, et al. Hodgkins disease and hypothermia: case report and review of literature. Ann Hematology 2002; 81:106-7.

13. Kulkarni A, Zlabek J, Farnen J, et al. Recurrent hypothermia and hypoglycemia in a patient with Hodgkin's disease. Haematologica 2006;91:ECR50.

14. Meert AP, Bherghmans T, Sculier JP. Hypothermia and Hodgkin disease: case report and review of literature. Acta Clin Belg 2006;61:252-4.

15. Koksal Y, Caliskan U, Unal E. Hypothermia in a child with Hodgkin's disease. J Pediater Hematol Oncol 2009;31:136-8.

16. Gundong M, Cicin I, Üstun C. Hypothermia in Hodgkin's disease: unexpected state; case report and review of the literature. Turk Onkoloji Dergisi 2013;28:41-3.

17. Shepshelovich D, Shpilberg 0, Lahav M, et al. Hodgkin lymphoma and hypothermia: case report and review of the literature. Acta Haematol 2014;131:227-30

18. Cowley AW. Long term control of arterial blood pressure. Physiol Rev 1992;72:231300

19. Alleva DG, Burger CJ, Elgert KD. Tumourinduced regulation of suppressor macrophage nitric oxide and TNF-alpha production. J Immunol 1994;153:1674-86

20. King EG, Bauzá GJ, Mella JR et al. Pathophysiologic mechanisms in septic shock. Lab Invest 2014;94:4-12.

21. Fonseca SG, Romão PRT, Figueiredo F, et al. TNF-alpha mediates the induction of nitric oxide synthase in macrophages but not in neutrophils in experimental cutaneous leishmaniasis. Eur J Immunol 2003;33:2297-306.

22. Foon KA. Biological response modifiers: the new immunotherapy. Cancer Res 1989;49:1621-39.

23. Koh PO. Melatonin regulates nitric oxide synthase expression in ischemic brain injury. J Vet Med Sci 2008;70:747-50.

24. Bilora F, Veronese F, Zancan A, et al. Autonomic dysfunction in Hodgkin and non-Hodgkin lymphoma: a paraneoplastic syndrome? Hematol Rep 2010;2:e8. 